\title{
Process Efficiency and Energy Consumption during the Ultrasound-Assisted Extraction of Bioactive Substances from Hawthorn Berries
}

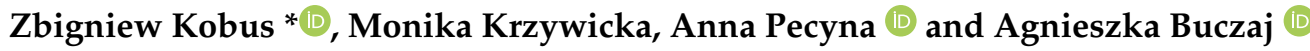 \\ Department of Technology Fundamentals, University of Life Sciences, 20-612 Lublin, Poland; \\ monika.krzywicka@up.lublin.pl (M.K.); anna.pecyna@up.lublin.pl (A.P.); agnieszka.buczaj@up.lublin.pl (A.B.) \\ * Correspondence: zbigniew.kobus@up.lublin.pl
}

check for

updates

Citation: Kobus, Z.; Krzywicka, M.; Pecyna, A.; Buczaj, A. Process Efficiency and Energy Consumption during the Ultrasound-Assisted

Extraction of Bioactive Substances from Hawthorn Berries. Energies 2021, 14, 7638. https://doi.org/10.3390/ en14227638

Academic Editor: Alberto-Jesus Perea-Moreno

Received: 17 October 2021 Accepted: 11 November 2021 Published: 15 November 2021

Publisher's Note: MDPI stays neutral with regard to jurisdictional claims in published maps and institutional affiliations.

Copyright: (c) 2021 by the authors. Licensee MDPI, Basel, Switzerland. This article is an open access article distributed under the terms and conditions of the Creative Commons Attribution (CC BY) license (https:/ / creativecommons.org/licenses/by/ $4.0 /)$.

\begin{abstract}
This study investigated the impact of sonication parameters on the efficiency of the extraction of bioactive substances from hawthorn berries. The ultrasonic treatment was performed in two modes: continuous and pulse. In the pulse mode, the samples were sonicated with the following processor settings: $1 \mathrm{~s}$ on- $2 \mathrm{~s}$ off. The effective ultrasonic processor times were 5,10 , and $15 \mathrm{~min}$, and the total extraction times were $15 \mathrm{~min}, 30 \mathrm{~min}$, and $45 \mathrm{~min}$. The content of total polyphenols and total anthocyanins was determined by a spectrophotometric method. We show that the operating mode of the processor affects extraction efficiency, energy consumption and unit energy inputs. Extraction supported by a pulsating ultrasonic field allowed saving from $20 \%$ to $51 \%$ of energy with a simultaneous higher efficiency of the process. In addition, we show that the unit energy consumption in the pulsed mode was about $40 \%$ to $68 \%$ lower than the energy consumption in the case of continuous operation.
\end{abstract}

Keywords: yield of extraction; energy consumption; pulsed ultrasound; polyphenols; anthocyanins; energy conversion

\section{Introduction}

In recent years, there has been a growing interest in the extraction and research of bioactive substances from lesser known biological materials due to their potential health benefits in the prevention of chronic diseases. One of the most valuable medicinal plants is hawthorn. This plant belongs to the genus Crataegus that occurs in Europe, Asia and North America [1]. Hawthorn berries are a source of polyphenolic compounds (procyanidins, flavanols, flavonols, C-glycosyl flavones, phenolic acids, anthocyanins and lignans) $[2,3]$ showing high antioxidant, anti-thrombotic, anti-inflammatory, anticarcinogenic and hypolipemic potential [4-14].

The key issue in obtaining biologically active compounds from plant materials is the choice of the extraction method. Various techniques are currently in use, such as: maceration, Soxhlet extraction, supercritical extraction, microwave-assisted extraction, pulsed electric field assisted extraction, and high pressure solvent extraction [15-18]. Ultrasound assisted extraction (UAE) has also been commonly applied [19-22].

UAE, next to the microwave of supercritical fluid extraction and pulsed electric field extraction, belongs to the so-called "green technologies" [23]. In accordance with the principles of green chemistry established by the U.S. Environmental Protection Agency [24], these technologies have a reduced environmental impact in terms of time and energy [24,25]. Compared to other methods, UAE has numerous advantages: a relatively short process duration, a small volume of consumed solvents, and a low cost of the equipment [26-28]. The inconvenience of using this method is the necessity to separate the extract from post-extraction residues [26]. The mechanism of extraction by ultrasound consists in disintegrating plant cells and releasing their contents into the extraction solvent [29]. The 
most important parameters of ultrasound-assisted extraction include: time and temperature of process, liquid-to-solid ratio, type, concentration and $\mathrm{pH}$ of the organic solvent, and elements related to the operation of the ultrasound system itself, such as: ultrasound intensity and frequency, system type (ultrasonic bath or ultrasonic probe) and ultrasound mode (continuous or pulsed) [30-33].

The impact of the majority of the parameters on extraction efficiency is well known. Extensive work has been devoted to the influence of the intensity and frequency of ultrasound on the yield of extraction of bioactive substances from the matrix of a solid.

An innovative solution when conducting ultrasound-assisted extraction is the use of the pulsed mode. A less known issue is how the operating mode of the ultrasound system affects the efficiency of the extraction. Most of the research works have focused on the use of a continuous ultrasonic field. So far, few authors have dealt with the process of assisting extraction with a pulsating acoustic field. Direct comparisons of the effects of the continuous and the pulsed modes of the ultrasonic processor on the extraction efficiency are also very limited. Pan et al. [34] found that there are no statically significant differences in time and efficiency of extraction between the modes of an ultrasonic processor, but pulsed ultrasound assisted extraction saved about $50 \%$ of electricity compared to continuous ultrasound. Similar results were obtained by Patience et al. [35] during the extraction of pectin from navel orange peels. There was no significant difference between continuous and pulsing irradiation despite the great difference in energy consumption (190 kJ vs. $80 \mathrm{~kJ})$. On the other hand, Christou et al. [36] during polyphenol recovery from mature and immature carobs, achieved a slightly higher efficiency when UAE was performed in the pulsed mode. The ultrasonic processor runs intermittently during pulse ultrasound assisted extraction (PUAE). The use of this mode reduces the effect of temperature, allowing the extraction of thermolabile compounds and reducing the degradation of bioactive compounds [37].

The depletion of energy resources has prompted the search for more economical methods of food processing and plant extracts preparation. The use of the pulsed mode can help to shorten the time of the ultrasonic treatment and increase the extraction efficiency. Due to their high medical importance, hawthorn fruits require proper processing and it seems that the extraction supported by a pulsating acoustic field can improve the quality of the final extracts as it involves gentler way of treating the raw material compared to the continuous mode. The confirmation of the positive effect of pulsed-assisted extraction could allow the practical application of this technique in both food and pharmaceutical industries.

Based on the current state of knowledge, it is not possible to unequivocally estimate the impact of the operating mode of ultrasonic generators on the extraction efficiency of bioactive substances. Hence, the aim of this study was to compare the effect of ultrasoundassisted extraction in pulsed and continuous mode on energy consumption, unit energy inputs and the content of selected bioactive substances in extracts from hawthorn berries.

\section{Materials and Methods}

\subsection{Raw Material}

The berries of the double-necked hawthorn (Crataegus laevigata) were selected as the raw material. Hawthorn fruits were harvested in the Lublin Upland. Immediately after harvesting, the raw material was dried in a freeze dryer. Then the material was crushed and divided into 5 fractions. Three fractions were selected for further research; they were obtained from the following sieves: fraction 1 sieve size $0.25-0.5 \mathrm{~mm}$, fraction 2 sieve size 0.5-1.0 mm, fraction 3 sieve size 1.0-2.0 $\mathrm{mm}$.

\subsection{Ultrasonic Treatment}

Four grams of ground hawthorn was put into the extraction cell and covered with an aqueous solution of ethyl alcohol at a concentration of $60 \%$. The solid/liquid ratio used in the extraction process by ultrasound was 1:12.5. Then, the extraction cell was placed in a cooling jacket connected to a water bath to stabilize the temperature. From the top, the extraction cell was closed with an ultrasonic probe with a diameter of $19 \mathrm{~mm}$. 
The experimental samples were sonicated with a VC750 ultrasound processor (Sonics and Materials Inc., USA) operating at a frequency of $20 \mathrm{kHz}$. The sonication was performed at three amplitudes: $12 \mu \mathrm{m}, 24 \mu \mathrm{m}$ and $36 \mu \mathrm{m}$.

These amplitudes correspond to $2.5,9.5$, and $19 \mathrm{~W} / \mathrm{cm}^{2}$ in the continuous mode and to $1.3,7.5$, and $14 \mathrm{~W} / \mathrm{cm}^{2}$ in the pulsed mode. In pulse mode, the samples were sonicated with the following processor setting: $1 \mathrm{~s}$ on- $2 \mathrm{~s}$ off. The times of ultrasonic treatment were 5, 10, and $15 \mathrm{~min}$, and the total extraction times were $15 \mathrm{~min}, 30 \mathrm{~min}$, and $45 \mathrm{~min}$, respectively. In continuous mode, the samples were sonicated for 5, 10, and $15 \mathrm{~min}$, and then held for 10, 20, and $30 \mathrm{~min}$ in the extraction cells to achieve the same extraction times as for the pulsed treatment. The obtained extracts were stored under refrigeration $\left(2{ }^{\circ} \mathrm{C}\right)$ and then collected for further chemical analyses.

\subsection{Determination of Total Phenolic Content (TPC)}

The content of polyphenols was determined by the spectrophotometric method using gallic acid as the reference standard. First, the sample extract $(0.2 \mathrm{~mL})$ was mixed with $2 \mathrm{~mL}$ Folin-Ciocalteu reagent and allowed to react for $3 \mathrm{~min}$. Next, $2 \mathrm{~mL}$ of $\mathrm{Na}_{2} \mathrm{CO}_{3}$ solution was added, and the mixture was made up to $25 \mathrm{~mL}$ with distilled water. After leaving the mixture for $30 \mathrm{~min}$ at room temperature in the dark, the absorbance at $760 \mathrm{~nm}$ was measured using a spectrophotometer (UV-1800; Shimadzu, Japan). The results are expressed as mg gallic acid equivalent per $1 \mathrm{~g}$ of dry matter ( $\mathrm{mg} \mathrm{GAE}^{-1}$ dry matter). The measurement was performed in three replicates for each sample [38].

\subsection{Determination of Total Anthocyanin Content (TAC)}

TAC was determined by the spectrophotometric method on the basis of absorbance measurements at various $\mathrm{pH}$ values [39]. First, the sample extract $(1.0 \mathrm{~mL})$ was mixed with $4 \mathrm{~mL}$ potassium chloride and sodium acetate buffers at $\mathrm{pH} 1.0$ and 4.5. After leaving the mixture for $15 \mathrm{~min}$ at room temperature the absorbance was measured at 520 and $700 \mathrm{~nm}$. The correct absorbance was determined from the formula:

$$
A=\left(A_{520}-A_{700}\right)_{p H 1.0}-\left(A_{520}-A_{700}\right)_{p H 4.5}
$$

The content of anthocyanins was expressed as a cyanidin 3-glucoside equivalent (Cy3-GE) in mg per $\mathrm{g}$ of dry matter on the basis of the following formula:

$$
T A C=\frac{A}{L \varepsilon} M_{w} \cdot N
$$

where:

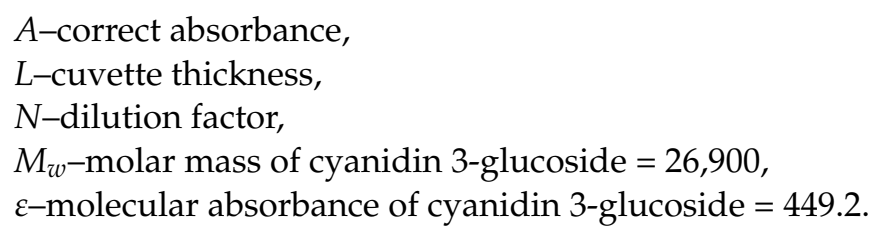

\subsection{Power Output and Unit Energy Consumption}

The power output (energy consumption) was measured by a wattmeter built-in the generator. The analysis of energy consumption of ultrasonic-assisted extraction was performed with respect to the polyphenol and anthocyanin contents obtained in the extract. The unit energy consumption was determined by the following formula:

$$
N=\frac{E}{m}
$$

where:

E-energy consumption (kJ),

$m$-mass of polyphenols or anthocyanins (g). 


\subsection{Statistical Analyses}

The obtained results were statistically analyzed with Statistica software via analysis of variance (ANOVA). The significance of the differences between the evaluated mean values (in figures) was analyzed with the Tukey test at a significance level of $p<0.05$.

\section{Results}

\subsection{Total Phenolic Content}

Hawthorn berries are an important source of many substances with high biological activity, including polyphenols. The effect of ultrasonic treatment parameters on the content of polyphenols in hawthorn extracts is shown in Figure 1. A large variation of the results was observed depending on the operating mode of the processor, the amplitude of the ultrasonic vibrations and the treatment time. The lowest content of polyphenols was obtained for continuous mode, amplitude of $12 \mu \mathrm{m}$ and time of $5 \mathrm{~min}$., and the highest for pulsed mode, amplitude of $36 \mu \mathrm{m}$ and time of $15 \mathrm{~min}$. The difference between the lowest and the highest content of polyphenols was almost $200 \%$. A statistically significant influence of all analyzed processing parameters on the content of TPC was found. Among the examined factors, the greatest influence was observed in the case of the amplitude of ultrasonic vibrations. The increase in the amplitude from $12 \mu \mathrm{m}$ to $36 \mu \mathrm{m}$ resulted in an increase in the content of polyphenols from $101 \%$ to $150 \%$. The second important factor was the time of the ultrasonic treatment. The increase in the treatment time from $5 \mathrm{~min}$ to $15 \mathrm{~min}$ resulted in an increase in the content of polyphenols in the range from $2.3 \%$ to $37 \%$. The third parameter was the mode of the ultrasonic processor. The difference in polyphenol content between the pulsed mode and the continuous mode ranged from $1.14 \%$ to $23 \%$.

\subsection{Total Anthocyanin Content}

Anthocyanins are natural plant pigments that, as biologically active ingredients, exhibit a wide range of activities. Figure 2 shows the effect of the type of treatment (continuous, pulsating) on the anthocyanin content of alcoholic extracts obtained from hawthorn.

The amplitude of ultrasonic vibrations had a statistically significant impact on the anthocyanin content. For both treatments (continuous, pulsating), a significant growth in the content of anthocyanins was observed with the increase in the value of the ultrasound amplitude. The rise in the vibration amplitude from $12 \mu \mathrm{m}$ to $36 \mu \mathrm{m}$ resulted in an increase in the content of polyphenols from $213 \%$ to even $500 \%$. The operating time was also an important parameter influencing the anthocyanin content. In general, an increase in the extraction time resulted in an elevation in the anthocyanin content. In the case of pulsed treatment, the differences ranged from $9.59 \%$ to $50 \%$ depending on the ultrasound amplitude. In the case of continuous mode for the amplitude of $12 \mu \mathrm{m}$, a rise in the content of anthocyanins by $108 \%$ was noticed, and for the amplitude of $24 \mu \mathrm{m}$, a rise by $44 \%$. In the case of the amplitude of $36 \mu \mathrm{m}$, a decrease in the content of anthocyanins was observed from the value of $0.144 \mathrm{mg}$ Cy3-GE/g d.m. for the time of $5 \mathrm{~min}$ to the value of $0.118 \mathrm{mg}$ Cy3-GE/g d.m. for the time of $15 \mathrm{~min}$. The observed phenomenon may indicate the decomposition of anthocyanins extracted with the use of higher amplitudes of ultrasonic vibrations. An important factor changing the anthocyanin extraction efficiency was also the operating mode of the ultrasonic processor. In this case, a strong interaction effect between the operating mode and the ultrasonic vibration amplitude value was observed. For the $12 \mu \mathrm{m}$ amplitude, no statistically significant influence of the operating mode was found, but for the amplitudes of $24 \mu \mathrm{m}$ and $36 \mu \mathrm{m}$, there were statistically significant differences between the continuous and the pulsed mode. 


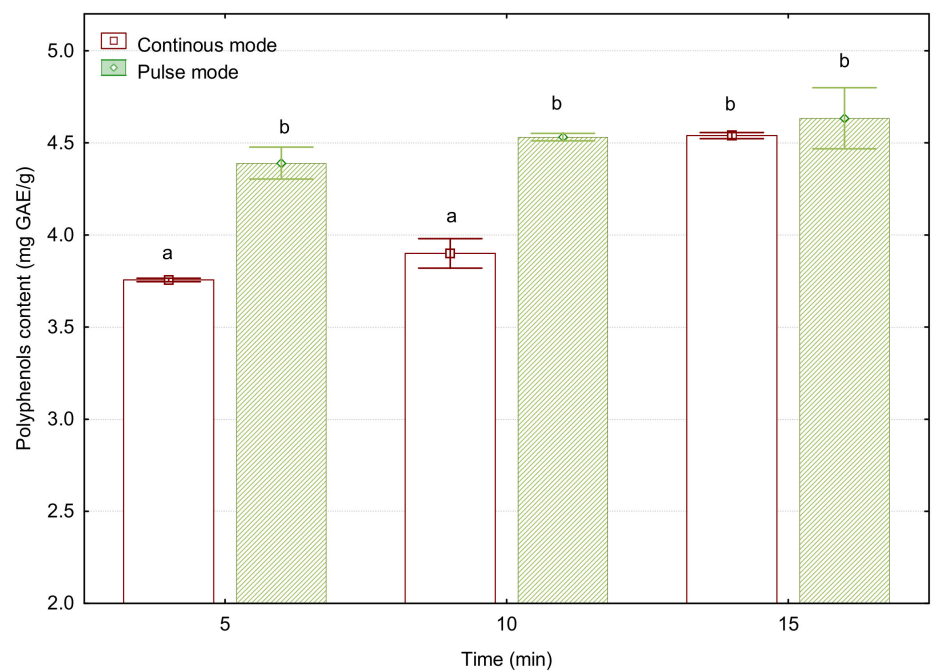

(a)

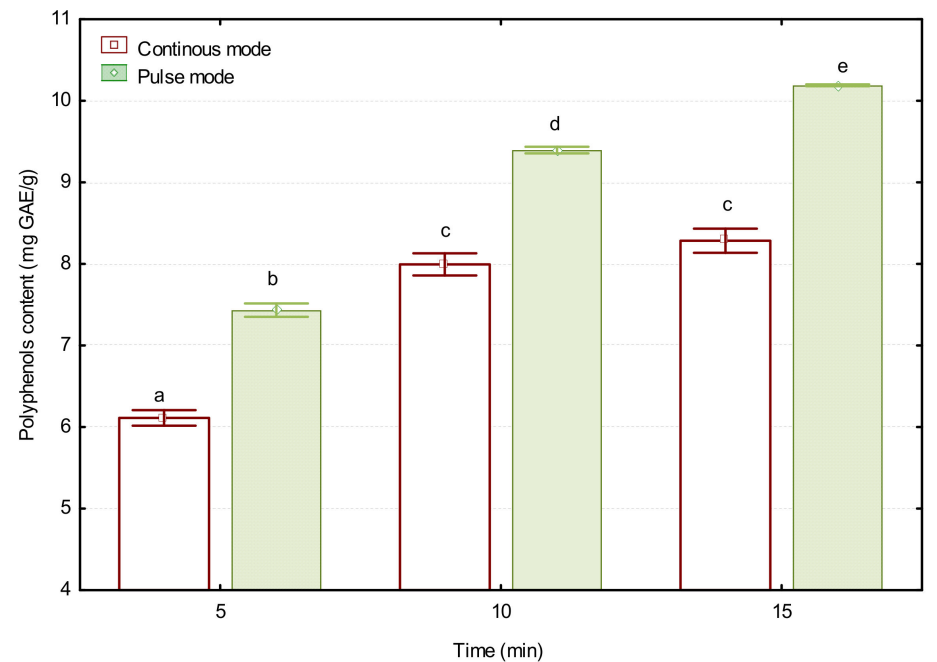

(b)

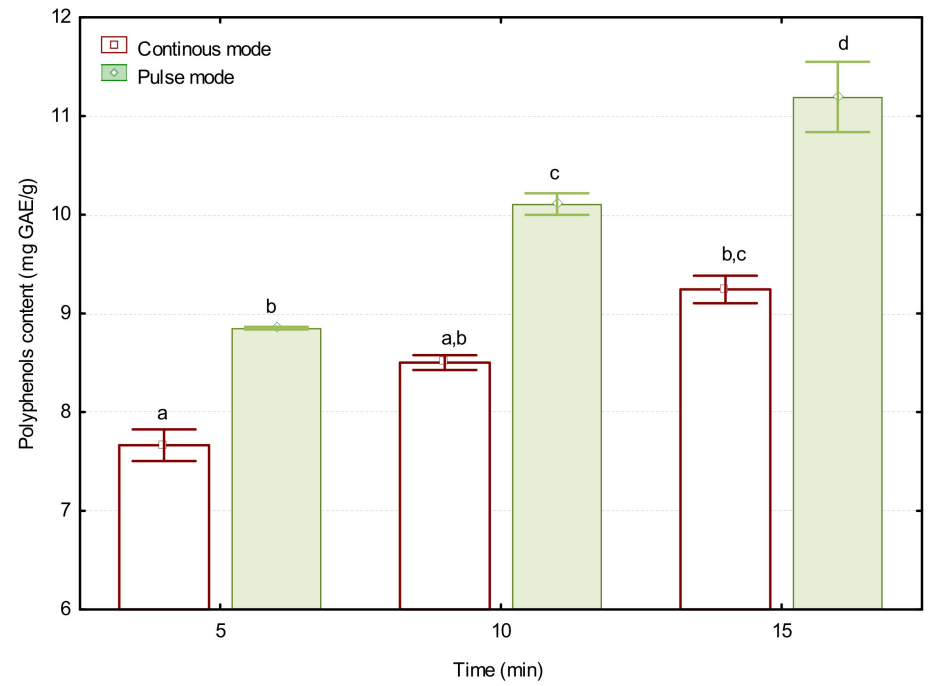

(c)

Figure 1. Effect of ultrasonic treatment parameters on the content of polyphenols (mg GAE/g d.m.) in hawthorn berries extracts: (a) amplitude $12 \mu \mathrm{m}$, (b) amplitude $24 \mu \mathrm{m}$, (c) amplitude $36 \mu \mathrm{m}$. The bars marked with the same letter are not statistically significantly different $(p<0.05)$. 


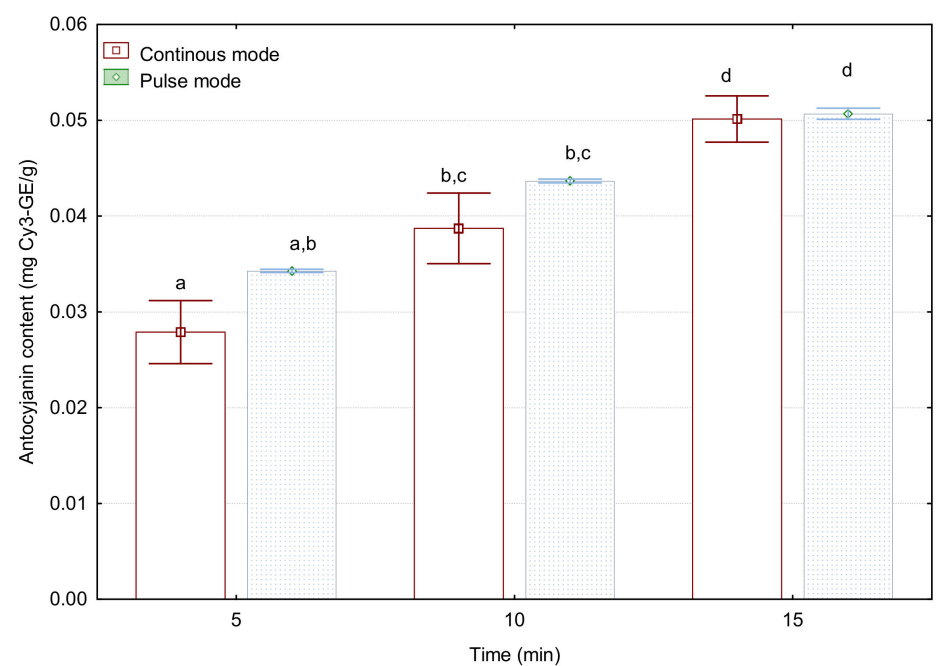

(a)

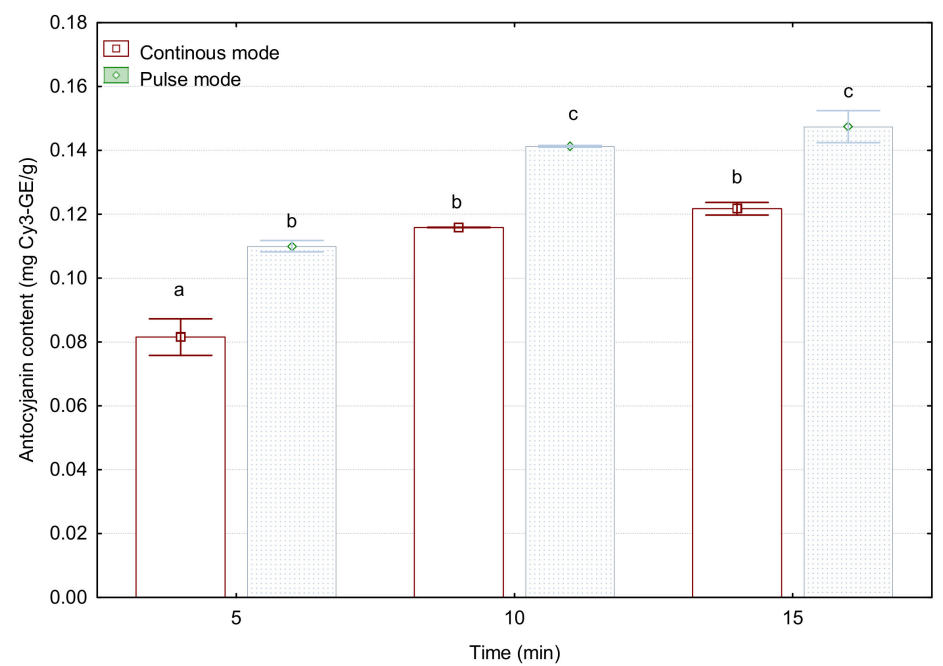

(b)

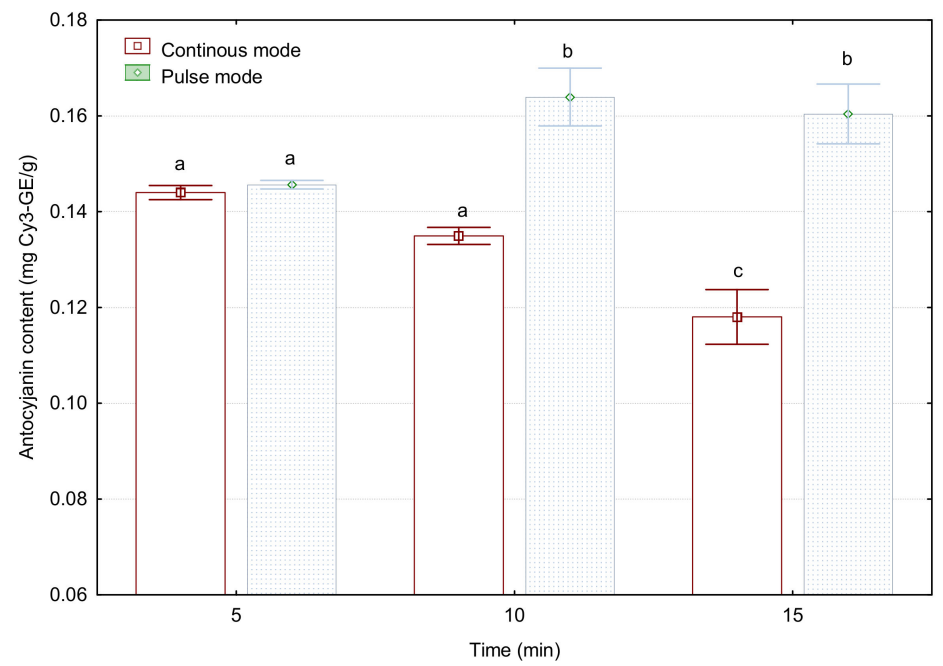

(c)

Figure 2. Effect of ultrasonic treatment parameters on the content anthocyanin [mg Cy3-GE/g d.m.] in hawthorn berries extracts: (a) amplitude $12 \mu \mathrm{m}$, (b) amplitude $24 \mu \mathrm{m}$, (c) amplitude $36 \mu \mathrm{m}$. The bars marked with the same letter are not statistically significantly different $(p<0.05)$. 


\subsection{Energy Consumption}

Figure 3 shows the effect of ultrasonic treatment on energy consumption during the extraction of bioactive substances from hawthorn berries. Significantly higher energy consumption was observed for the continuous mode. The effect of the processor mode on the extraction efficiency depended on the amplitude of the ultrasonic vibrations. The greatest difference was recorded for the amplitude of $12 \mu \mathrm{m}$ and amounted to approx. 51\%. As the ultrasound intensity increased, the differences in energy consumption decreased and amounted to $20 \%$ and $26 \%$ for the amplitudes of $24 \mu \mathrm{m}$ and $36 \mu \mathrm{m}$, respectively. It is worth noticing that there was a non-linear relationship between the amplitude of ultrasonic vibrations and energy consumption. A double increase in the amplitude of the ultrasonic vibrations resulted in an energy consumption that was about 4 times higher in the case of the continuous mode and about 6 times higher in the case of the pulsed mode. A further increase in the vibration amplitude had an even greater impact on the increase in energy consumption by the ultrasonic processor. The amount of energy consumed by the sonicator has a significant impact on the amount of acoustic energy emitted, which in turn translates into the efficiency of extracting bioactive substances from plant tissue.

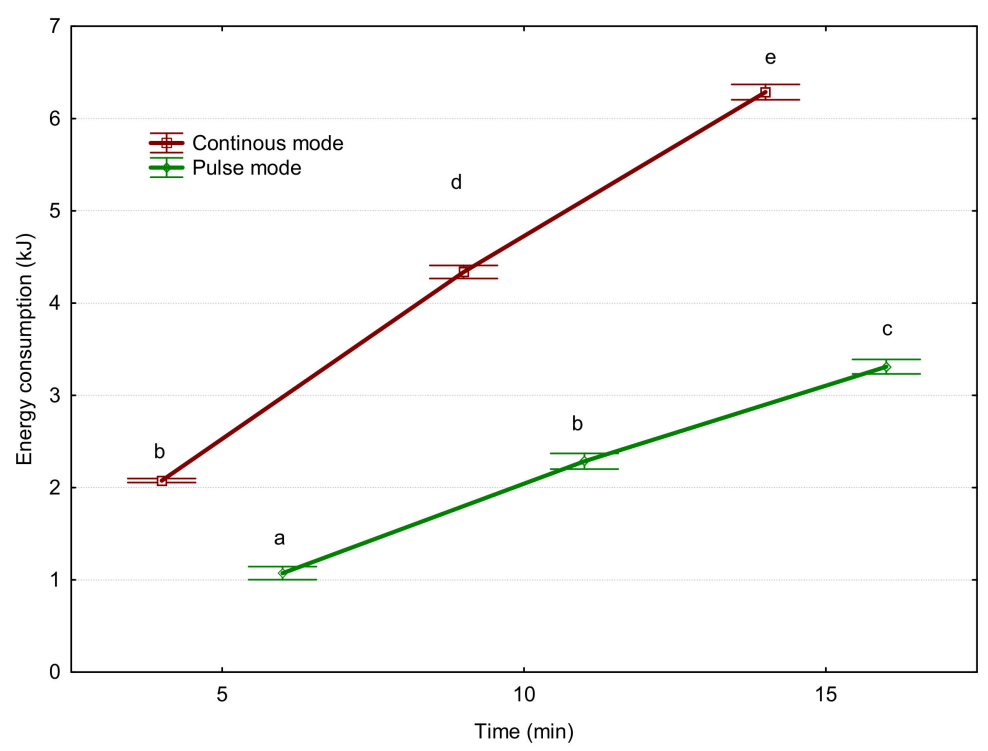

(a)

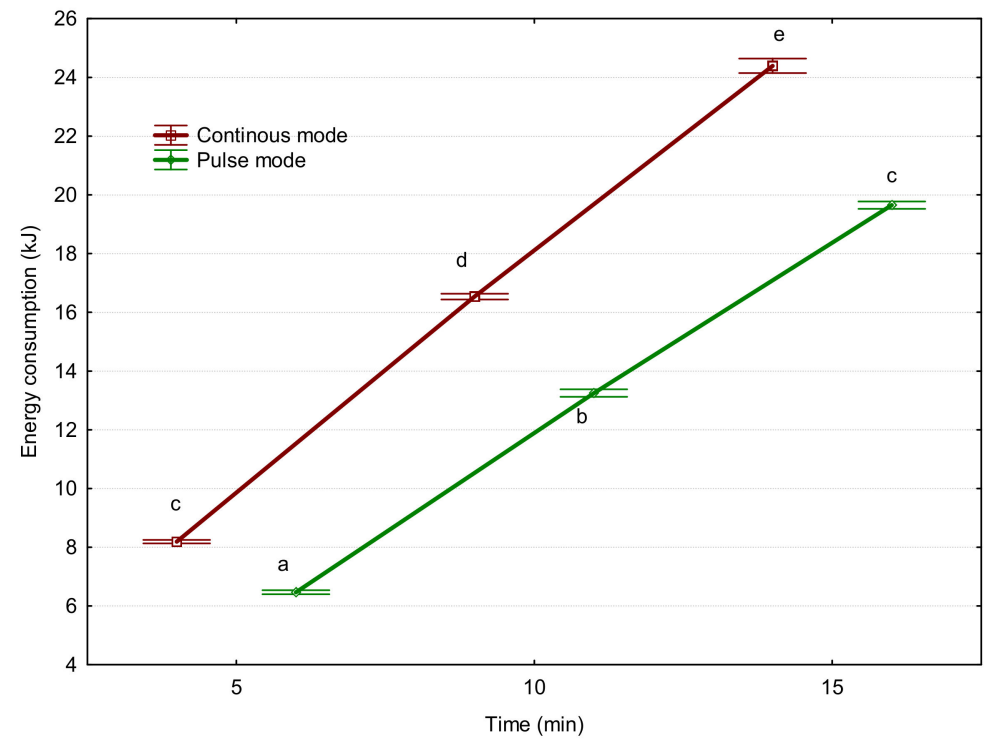

(b)

Figure 3. Cont. 


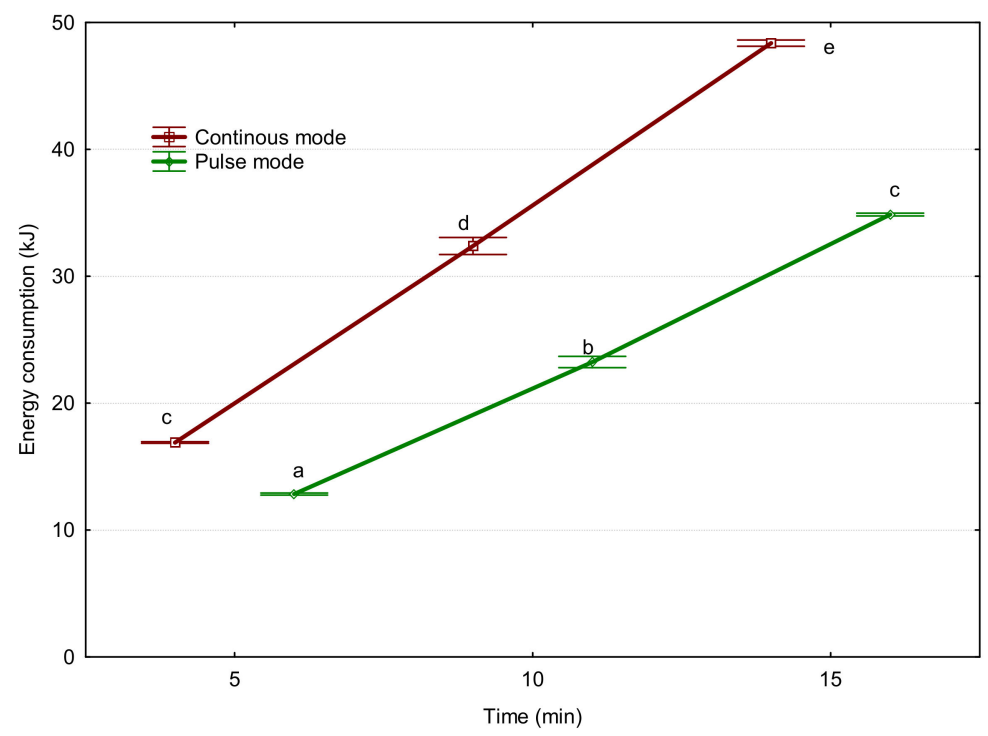

(c)

Figure 3. Impact of ultrasonic treatment parameters on energy consumption during the extraction of bioactive substances from hawthorn berries: (a) amplitude $12 \mu \mathrm{m}$, (b) amplitude $24 \mu \mathrm{m}$, (c) amplitude $36 \mu \mathrm{m}$. The bars marked with the same letter are not statistically significantly different $(p<0.05)$.

\subsection{Unit Energy Consumption during Polyphenol Extraction}

Figure 4 shows the effect of ultrasonic treatment on the unit energy consumption during the extraction of polyphenols from hawthorn berries. Due to the fact that the pulsed processing enabled achieving a higher extraction efficiency, with a simultaneous lower energy consumption, the differences between the tested processor modes, expressed in the form of unit energy inputs, increased significantly. This effect was strictly dependent on the amplitude of ultrasonic vibrations. For the amplitude of $12 \mu \mathrm{m}$ the unit energy inputs in the pulsed mode accounted for about $40-54 \%$ of the unit inputs in the continuous mode. In the case of the $24 \mu \mathrm{m}$ amplitude, the ratio ranged from $62 \%$ to $68 \%$, and in the case of the $36 \mu \mathrm{m}$ amplitude, it ranged between 58 and $67 \%$. The increase in vibration amplitude resulted in a significant increase in energy inputs per unit of extracted polyphenols. In the case of the amplitude of $36 \mu \mathrm{m}$ the unit energy consumption was higher by approx. $416 \%$ to $983 \%$ compared to the unit energy determined with an amplitude of $12 \mu \mathrm{m}$. A similar tendency was observed for the time of extraction. Extending the extraction time from 5 to 15 min resulted in an increase in unit energy consumption up to $259 \%$. 


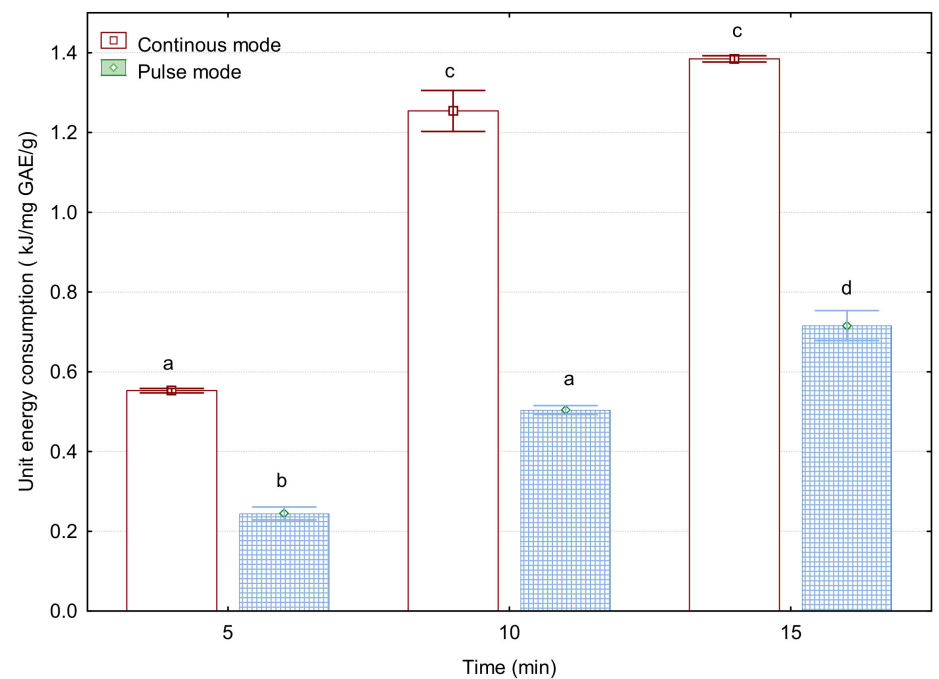

(a)

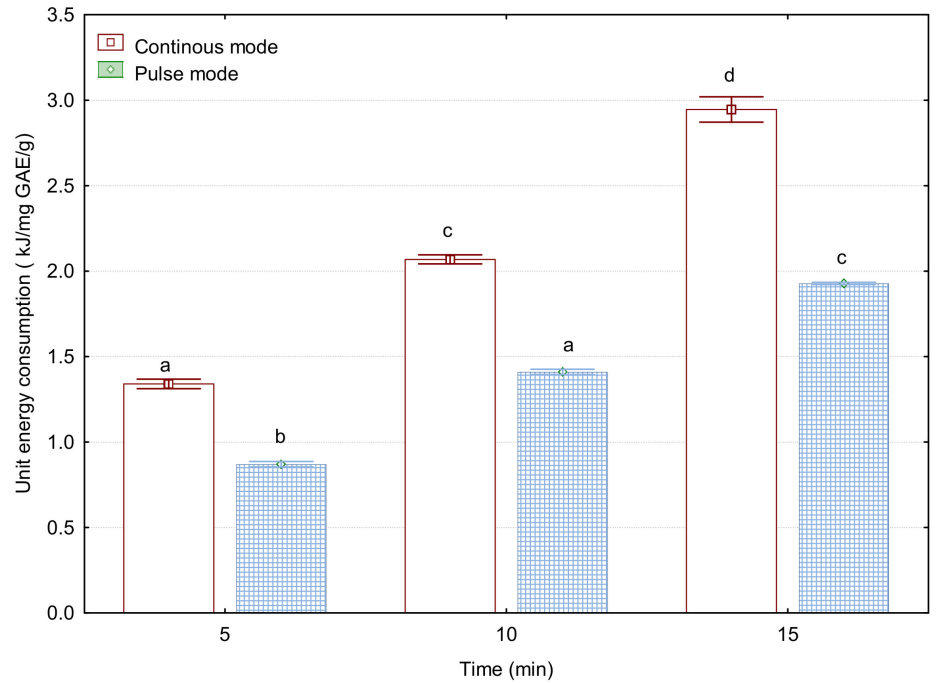

(b)

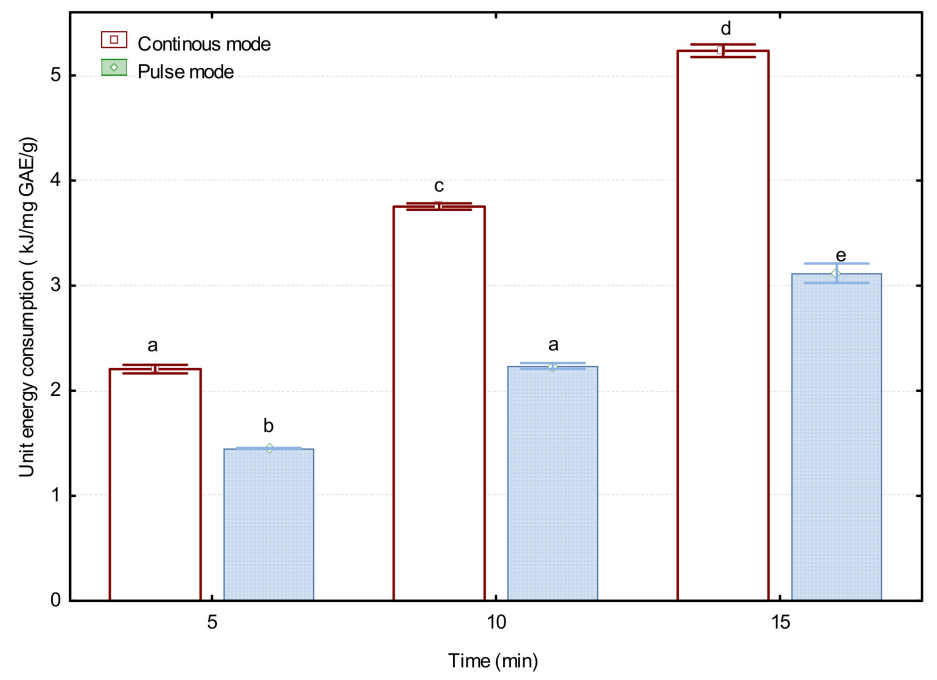

(c)

Figure 4. Impact of ultrasonic treatment parameters on the unit energy inputs during the extraction of polyphenols from hawthorn berries: (a) amplitude $12 \mu \mathrm{m}$, (b) amplitude $24 \mu \mathrm{m}$, (c) amplitude $36 \mu \mathrm{m}$. The bars marked with the same letter are not statistically significantly different $(p<0.05)$. 


\subsection{Unit Energy Consumption during the Extraction of Anthocyanins}

Figure 5 shows the effect of the ultrasonic treatment parameters on the unit energy inputs during the extraction of anthocyanins from hawthorn berries.

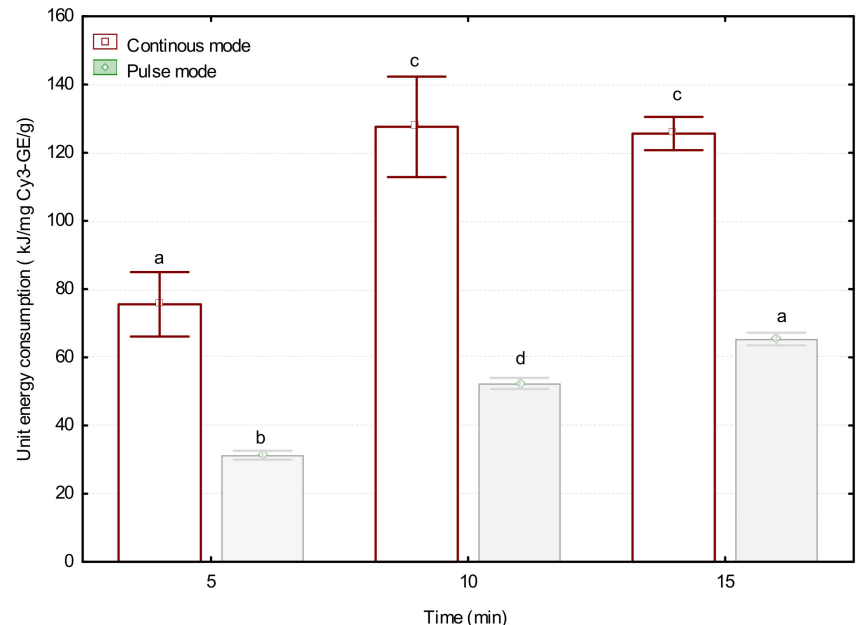

(a)

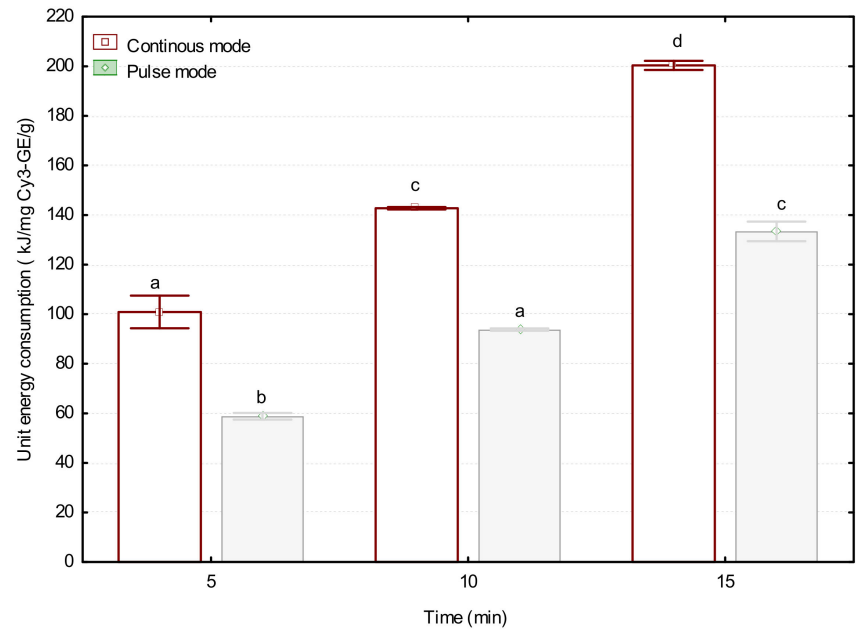

(b)

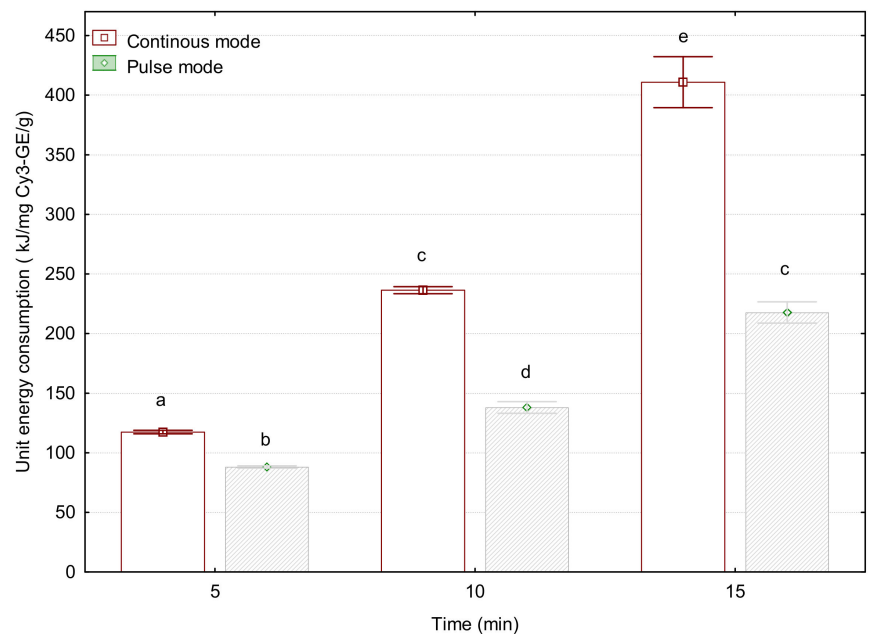

(c)

Figure 5. Impact of ultrasonic treatment parameters on the unit energy inputs during the extraction of anthocyanins from hawthorn berries: (a) amplitude $12 \mu \mathrm{m}$, (b) amplitude $24 \mu \mathrm{m}$, (c) amplitude $36 \mu \mathrm{m}$. The bars marked with the same letter are not statistically significantly different $(p<0.05)$. 
The unit energy consumption during the extraction of anthocyanins was about 100 higher than in the case of the extraction of polyphenols. This was mainly due to the lower content of these substances in hawthorn berries compared to polyphenols. The nature of the impact of the extraction parameters on the unit energy consumption for anthocyanins was similar to that during the extraction of polyphenols and depended on the amplitude of the ultrasonic vibrations.

In the case of an amplitude of $12 \mu \mathrm{m}$, the unit energy inputs in the pulsating mode accounted for about 38-55\% of the energy inputs in the continuous mode. For the $24 \mu \mathrm{m}$ amplitude, the ratio ranged from 56 to $69 \%$, and for the $36 \mu \mathrm{m}$ amplitude, between 53 and $75 \%$.

The amplitude of the ultrasonic vibrations had a significant impact on the amount of energy inputs, but much smaller than that observed for the extraction of polyphenols. In the case of the amplitude of $36 \mu \mathrm{m}$, the unit energy consumption was higher by approx. $184 \%$ to $350 \%$ compared to the unit energy determined with the amplitude of $12 \mu \mathrm{m}$. A similar tendency was observed for the time of treatment. Extending the extraction time from 5 to 15 min resulted in an increase in energy consumption up to $216 \%$.

\section{Discussion}

In none of the available reports, the analysis of the content of TPC and TAC, with the use of $C$. laevigata fruits was undertaken, therefore, the discussion referred to other varieties of hawthorn. Based on the literature review, it can be concluded that the TPC values may range from $2.9 \mathrm{mg} \mathrm{GAE} / \mathrm{g} \mathrm{d.w.} \mathrm{[40]} \mathrm{to} 96.9 \mathrm{mg} \mathrm{GAE} / \mathrm{g} \mathrm{d.w}$. depending on the species [41]. Abbaspour-Gilandeh et al. [42] showed that the TPC value was $79.82 \pm 2.42 \mathrm{mg}$ GAE/g d.w. in fresh hawthorn fruits. Żurek et al. [16] extracted shredded and previously freeze-dried berries from hawthorn with ethanol in two concentrations (50 and 70\% v/v). The extraction was carried out at the temperature of $20 \pm 2{ }^{\circ} \mathrm{C}$, for 2 and $24 \mathrm{~h}$. The value of TPC after $2 \mathrm{~h}$ in $50 \%$ and $70 \%$ solvent was respectively, $47.9 \pm 0.2$ and $54.7 \pm 0.0 \mathrm{mg} \mathrm{GAE} / \mathrm{g} \mathrm{d.m.,} \mathrm{and} \mathrm{after} 24 \mathrm{~h}$, it was, respectively, $46.5 \pm 0.0$ and $54.8 \pm 0.0 \mathrm{mg} \mathrm{GAE} / \mathrm{g} \mathrm{d.m}$. Ebrahimzadeh et al. [43] found that the TPC value of alcoholic extracts of hawthorn C. pentaegin fruit was $85.15 \mathrm{mg} \mathrm{GAE} / \mathrm{g}$ of extracted powder. A similar value $(96.9 \pm 4.3 \mathrm{mg}$ GAE/g of dry weight) was obtained by Liu et al. [41]. Tadic et al. [44] in the hawthorn extract extracted with 70\% ethanol obtained 35.40 mg GAE/g d.m. Comparable values were obtained by Li et al. [45] (31.58 mg GAE/g d.w.). The values found in our own research ranged from 3.32 to $11.19 \mathrm{mg}$ GAE/g d.m. and are closest to the results of Froehlicher et al. [46] (12.26 mg GAE/g d.w.) who used fruits of C. pinnatifida Bge in their experiments.

Literature data on the content of anthocyanins in hawthorn berries are limited. Only Froehlicher et al. [46] indicated that the content of anthocyanins in fresh C. monogyna berries is 0.58 eq. cyanidin-3-O-glucoside/g d.w., and that in dried is berries 0.15 eq. cyanidin-3-O-glucoside/g d.w. The results of our experiments showed that these values ranged from 0.024 to $0.164 \mathrm{mg}$ eq. cyanidin-3-O-glucoside/g d.m.

The intensity of ultrasound used to extract bioactive substances from plants depends on the type of compound to be extracted and the kind of solid matrix. In general, the efficiency of ultrasound-assisted extraction increases with the growth of ultrasound intensity and decreases when a certain intensity level is exceeded. This phenomenon can be explained by the more intense formation and collapse of cavitation bubbles with increasing ultrasound intensity. The size of cavitation bubbles is proportional to the intensity of the ultrasonic wave $[47,48]$. Larger cavitation bubbles generate a stronger shock wave during the collapse, which is responsible for a greater fragmentation of the plant tissue. Another phenomenon responsible for the increase in the extraction efficiency with the increase in the intensity of ultrasound is the rise in the intensity of mechanical vibrations in the solvent, which results in better penetration of the plant tissue by the solvent and higher diffusion coefficients.

A rise in the intensity of ultrasound also leads to an increase of the number of cavitation bubbles. When a certain limit is exceeded, this phenomenon becomes disadvantageous as 
it leads to inter-bubble collision and reduces the damaging effect of cavitation bubbles [49]. A large number of cavitation bubbles at the surface of the ultrasonic probe hinders energy transmission to the solvent and lowers the extraction efficiency [50]. In addition, highintensity ultrasound can degrade bioactive substances, which results in lower extraction efficiency. Gonzalez observed a linear relationship between the intensity of ultrasound and the efficiency of extraction of polyphenols and flavonoids from grape pomace [51]. In turn, Al-Dhabi et al. observed an increase in the extraction efficiency of phenolic compounds from waste spent coffee grounds when the ultrasound power increased from $100 \mathrm{~W}$ to $244 \mathrm{~W}$ and a decrease in efficiency when the ultrasound power exceeded the level of $250 \mathrm{~W}$ [52].

In our experiment, a positive and statistically significant effect of ultrasound intensity on the extraction efficiency was observed for both TPC and TAC. These increases were significant and ranged from 101 to $500 \%$ depending on the type of the extracted component. It should also be noted that the amplitude of ultrasonic vibrations was the most important parameter among all variables in the experiment influencing the extraction efficiency.

Another important factor influencing the yield of bioactive substances is the extraction time. The impact of this variable has been widely researched and described in the literature. Initially, extending the extraction time increases the efficiency of the process, but after exceeding a certain limit value, further processing does not result in a rise in efficiency or even causes its decrease. In the initial stage of extraction, the effect of ultrasound causes swelling, fragmentation and the formation of pores in the plant tissue. All of these factors increase solute transfer to the surrounding solvent. However, further exposure to ultrasound, with a simultaneous decrease in the concentration of the soluble substance in the plant tissue, causes structural damage to the extracted substance. The described trend was reported for antioxidant polysaccharide extraction from T. quadrispinosa (sijiaoling stem) [53] and grapefruit peel [54].

A positive effect of treatment time was noted during the extraction of pectin from grape pomace [55] and phenolic compounds and anthocyanins from jabuticaba peel [56], while a negative linear effect of time on the yield was reported for sour orange peel pectin [57] and phenolic compounds from powdered shell coconut (Cocos nucifera) [58].

Our research confirmed the positive effect of ultrasonic treatment time on the yield of bioactive substances. The increase in efficiency varied within wide ranges and amounted from 2.3 to $50 \%$ depending on the type of the extracted component, the applied operating mode of the ultrasonic processor and the amplitude of ultrasonic vibrations. In the case of anthocyanins, a slight but statistically insignificant decrease in extraction efficiency was observed.

The next analyzed parameter of ultrasound-assisted extraction was the duty cycle of the ultrasonic processor. The number of reports on this topic is significantly limited. A direct comparison of the influence of continuous and pulsed modes on the extraction efficiency was found only in the work of Pan et al. [34] who extracted polyphenols from pomegranate peel. The authors found that there was no significant difference in extraction efficiency between the tested modes. However, they showed that the pulsed ultrasonic field saved about $50 \%$ of energy compared to the continuous one.

In our research, a positive and statistically significant effect of the mode of the ultrasonic processor on the extraction efficiency was observed for both groups of bioactive substances. The elevation in extraction efficiency with the use of a pulsating acoustic field ranged from 1.14 to $34 \%$ and depended on the applied amplitude and the processing time.

The acoustic energy emitted by the ultrasonic processor is an important parameter during the extraction of bioactive substances. It should be noted that immediately after starting, the processor does not work with all its power and achieves its maximum power after a certain time lasting from a few to a dozen of hundredths of a second. This means that, in the case of a pulsed mode, the total energy emitted by the ultrasonic processor is much lower than in the case of a continuous mode. This was very evident in our experiment, where we observed a lower energy consumption from $20 \%$ to $51 \%$ for pulsed operation, 
despite the application of the same ultrasonic vibration amplitude. This phenomenon may also explain why the effect of the pulsed treatment in some cases is comparable to the effect of the continuous mode.

The increase in energy consumption with extraction time is characterized by a linear relationship. This means that no changes occurred during sonication that would affect the properties of the extraction solvent, including viscosity and acoustic impedance. Due to this, the amplitude of the ultrasonic vibration had a much greater effect on the extraction efficiency compared to the time of treatment. The same percentage elevation in the ultrasonic vibration amplitude as that in the extraction time resulted in a much greater amount of energy transferred to the extraction system.

The influence of the ultrasonic treatment parameters on unit energy consumption during the extraction of bioactive substances is relatively poorly described in the literature. Kobus et al. [59] showed that an important factor determining the energy consumption during ultrasonic extraction is the appropriate selection of the solvent. Energy efficiency analysis has shown that using $60 \%$ ethanol allows obtaining the lowest unit energy input. The ultrasonic processor consumes more energy in liquids with higher acoustic impedance. Hence, the energy generated by the sonicator during water extraction is higher than during the extraction with ethanol as a solvent [60].

The increase in unit energy consumption with the processing time is caused by the specificity of the extraction process. In the initial phase of the extraction process, the soluble substances leach quickly, which results in high extraction efficiency with low energy expenditure. With time, the amount of soluble substance in the solid matrix decreases and it is transported to the main mass of the solvent mainly by diffusion. This means that with the same energy inputs, the amount of the extracted substance is much smaller than in the initial phase of the process. In the final phase of the process, the amount of soluble substance is small and its extraction is more difficult, which results in a significant increase in unit energy inputs. The use of sonication significantly accelerates the extraction process, which contributes to the reduction of unit energy inputs in the initial stage of the process. However, too long an ultrasonic treatment adversely affects the value of this indicator, because the benefits of extracting an additional portion of a bioactive substance are disproportionate compared to the additional energy consumption involved.

\section{Conclusions}

The conducted research has shown that the efficiency of the ultrasonic extraction process of bioactive substances from hawthorn berries depends on the operating parameters of the ultrasonic processor. Among the examined factors, the greatest effect was observed for the amplitude of ultrasonic vibrations (101\% to $500 \%)$, then for the extraction time ( $2.3 \%$ to $50 \%$ ), and finally for the ultrasonic processor mode (1.14\% to $34 \%)$.

This study also showed the impact of the ultrasound mode on energy consumption and unit energy inputs. Extraction assisted with a pulsating ultrasonic field saved from $20 \%$ to $51 \%$ of energy with a simultaneous higher efficiency of the process.

Unit energy consumption in the case of the pulsed mode constituted about $40 \%$ to $68 \%$ of unit energy consumption for the continuous mode. This means that for extracting bioactive substances from hawthorn berries, the pulsed treatment is a much more effective method than the continuous one. The practical application of the results of this study can be performed by manufacturers of dietary supplements and drugs from hawthorn in order to optimize the extraction parameters. The fact that the processor operating mode has various effects on the efficiency of extraction of individual bioactive substances of hawthorn requires further research.

Author Contributions: Conceptualization, Z.K.; methodology, Z.K.; software, A.P.; validation, Z.K., M.K. and A.P.; formal analysis, Z.K. and M.K.; investigation, M.K. and Z.K.; resources, A.P.; data curation, A.B.; writing—original draft preparation, Z.K. and M.K.; writing-review and editing, Z.K., M.K. and A.P.; visualization, A.B.; supervision, Z.K.; project administration, A.B.; funding acquisition, Z.K. All authors have read and agreed to the published version of the manuscript. 
Funding: This research received no external funding.

Institutional Review Board Statement: Not applicable.

Informed Consent Statement: Not applicable.

Data Availability Statement: Data sharing not applicable.

Conflicts of Interest: The authors declare no conflict of interest.

\section{References}

1. Zhao, H.; Tian, B. China Fruit-Plant Monograph, Hawthorn Flora; Zhongguo Linye Press: Beijing, China, 1996 ; pp. 13-15.

2. Yang, B.; Liu, L. Composition and health effects of phenolic compounds in hawthorn (Crataegus spp.) of different origins. J. Sci. Food Agric. 2012, 92, 1578-1590. [CrossRef]

3. Cao, G.Y.; Feng, Y.X.; Qin, X.Q. Analysis of the chemical constituents of hawthorn fruits and their quality evaluation. Acta Pharm. Sin. 1995, 30, 138-143.

4. Li, L.Z.; Gao, P.Y.; Song, S.J.; Yuan, Y.Q.; Liu, C.T.; Huang, X.X.; Liu, Q.B. Monoterpenes and flavones from the leaves of Crataegus pinnatifida with anticoagulant activities. J. Funct. Foods 2015, 12, 237-245. [CrossRef]

5. Han, X.; Li, W.; Huang, D.; Yang, X. Polyphenols from hawthorn peels and fleshes differently mitigate dyslipidemia, inflammation and oxidative stress in association with modulation of liver injury in high fructose diet-fed mice. Chem. Biol. Interact. 2016, 257, 132-140. [CrossRef]

6. Verma, S.K.; Jain, V.; Verma, D.; Khamesra, R. Crataegus oxyacantha-A cardioprotective herb. J. Herb. Med. Toxicol. 2007, 1, 65-71.

7. Kao, E.S.; Wang, C.J.; Lin, W.L.; Yin, Y.F.; Wang, C.P.; Tseng, T.H. Anti-inflammatory potential of flavonoid contents from dried fruit of Crataegus pinnatifida In Vitro and In Vivo. J. Agric. Food Chem. 2005, 53, 430-436. [CrossRef]

8. Dong, H.; Zhang, T.P.; Peng, S.M. Extraction of sitosterol from hawthorn fruits and effect of sitosterol on immunological function and serum lipid. Nat. Prod. Res. Dev. 2009, 21, 60-63.

9. Ma, L.; Xu, G.B.; Tang, X.; Zhang, C.; Zhao, W.; Wang, J.; Chen, H. Anti-cancer potential of polysaccharide extracted from hawthorn (Crataegus) on human colon cancer cell line HCT116 via cell cycle arrest and apoptosis. J. Funct. Foods 2020, 64, 103677. [CrossRef]

10. Chang, W.T.; Dao, J.; Shao, Z.H. Hawthorn: Potential roles in cardiovascular disease. Am. J. Chin. Med. 2005, 33, 1-10. [CrossRef]

11. Kim, S.H.; Kang, K.W.; Kim, K.W.; Kim, N.D. Procyanidins in Crataegus extract evoke endothelium-dependent vasorelaxation in rat aorta. Life Sci. 2000, 67, 121-131. [CrossRef]

12. Pittler, M.H.; Schmidt, K.; Ernst, E. Hawthorn extract for treating chronic heart failure: Meta-analysis of randomized trials. Am. J. Med. 2003, 114, 665-674. [CrossRef]

13. Zhang, Z.S.; Ho, W.K.K.; Huang, Y.; Chen, Z.Y. Hypocholesterolemic activity of hawthorn fruit is mediated by regulation of cholesterol-7alpha-hydroxylase and acyl CoA: Cholesterol acyltransferase. Food Res. Int. 2002, 35, 885-891. [CrossRef]

14. Shao, F.; Gu, L.; Chen, H.; Liu, R.; Huang, H.; Chen, L.; Yang, M. Evaluation of hypolipidemic and antioxidant effects in phenolrich fraction of Crataegus pinnatifida fruit in hyperlipidemia rats and identification of chemical composition by ultraperformance liquid chromatography coupled with quadropole time-of-flight mass spectrometry. Pharmacogn. Mag. 2017, 13, 725-731.

15. Zhang, Q.; Lin, L.; Ye, W. Techniques for extraction and isolation of natural products: A comprehensive review. Chin. Med. 2018, 20, 1-26. [CrossRef]

16. Żurek, N.; Kapusta, I.; Cebulak, T. Wpływ warunków ekstrakcji na potencjał przeciwutleniający wyciągów z kwiatów, liści i owoców głogu (Crataegus $\times$ Macrocarpa L.). Żywność Nauka Technol. Jakość 2020, 27, 130-141. [CrossRef]

17. Rocchetti, G.; Blasi, F.; Montesano, D.; Ghisoni, S.; Marcotullio, M.C.; Sabatini, S.; Cossignani, L.; Lucini, L. Impact of conventional/non-conventional extraction methods on the untargeted phenolic profile of Moringa oleifera leaves. Food Res. Int. 2019, 115, 319-327. [CrossRef]

18. Rodríguez-Pérez, C.; Gilbert-López, B.; Mendiola, J.A.; Quirantes-Piné, R.; Segura-Carretero, A.; Ibáñez, E. Optimization of microwave-assisted extraction and pressurized liquid extraction of phenolic compounds from Moringa oleifera leaves by multiresponse surface methodology. Electrophoresis 2016, 37, 1938-1946. [CrossRef]

19. Knorr, D.; Zenker, M.; Heinz, V.; Lee, D.U. Applications and potential of ultrasonics in food processing. Trends Food Sci. Technol. 2004, 15, 261-266. [CrossRef]

20. Chandrapala, J.; Oliver, C.; Kentish, S.; Ashokkumar, M. Ultrasonics in food processing-Food quality assurance and food safety. Trends Food Sci. Technol. 2012, 26, 88-98. [CrossRef]

21. Martín-García, B.; Razola-Díaz, M.D.C.; Gómez-Caravaca, A.M.; Benítez, G.; Verardo, V. Setup of an Ultrasonic-Assisted Extraction to Obtain High Phenolic Recovery in Crataegus monogyna Leaves. Molecules 2021, 26, 4536. [CrossRef]

22. Sadeghi-Kiakhani, M.; Tehrani-Bagha, A.R.; Safapour, S.; Eshaghloo-Galougahi, S.; Etezad, S.M. Ultrasound-assisted extraction of natural dyes from Hawthorn fruits for dyeing polyamide fabric and study its fastness, antimicrobial, and antioxidant properties. Environ. Dev. Sustain. 2021, 23, 9163-9180. [CrossRef]

23. Turrini, F.; Donno, D.; Beccaro, G.L.; Zunin, P.; Pittaluga, A.; Boggia, R. Pulsed Ultrasound-Assisted Extraction as an Alternative Method to Conventional Maceration for the Extraction of the Polyphenolic Fraction of Ribes nigrum Buds: A New Category of Food Supplements Proposed by The FINNOVER Project. Foods 2019, 8, 466. [CrossRef] 
24. Chemat, F.; Rombaut, N.; Meullemiestre, A.; Turk, M.; Perino, S.; Fabiano-Tixier, A.S.; Abert-Vian, M. Review of green food processing techniques. Preservation, transformation, and extraction. Innov. Food Sci. Emerg. Technol. 2017, 41, 357-377. [CrossRef]

25. United States Environmental Protection Agency. Green Chemistry's 12 Principles. Available online: https://www.epa.gov/ greenchemistry / basics-green-chemistry\#twelve (accessed on 26 July 2019).

26. Babić, S.; Petrović, M.; Kaštelan-Macan, M. Ultrasonic solvent extraction of pesticides from soil. J. Chromatogr. A 1998, 823, 3-9. [CrossRef]

27. Hou, M.; Hu, W.; Wang, A.; Xiu, Z.; Shi, Y.; Hao, K.; Sun, X.; Cao, D.; Lu, R.; Sun, J. Ultrasound-assisted extraction of total flavonoids from Pteris cretica L.: Process optimization, HPLC analysis, and evaluation of antioxidant activity. Antioxidants 2019, 8, 425. [CrossRef]

28. Sharayei, P.; Azarpazhooh, E.; Zomorodi, S.; Ramaswamy, H.S. Ultrasound assisted extraction of bioactive compounds from pomegranate (Punica granatum L.) peel. LWT Food Sci. Technol. 2019, 101, 342-350. [CrossRef]

29. Toma, M.; Vinatoru, L.; Paniwnyk, L.; Mason, T.J. Investigation of the effects of ultrasound on vegetal tissues during solvent extraction. Ultrason. Sonochem. 2001, 8, 137-142. [CrossRef]

30. Lin, X.; Wu, L.; Wang, X.; Yao, L.; Wang, L. Ultrasonic-assisted extraction for flavonoid compounds content and antioxidant activities of India Moringa oleifera L. leaves: Simultaneous optimization, HPLC characterization and comparison with other methods. J. Appl. Res. Med. Aromat. Plants 2021, 20, 100284. [CrossRef]

31. Jaeschke, D.P.; Rech, R.; Marczak, L.D.F.; Mercali, G.D. Ultrasound as an alternative technology to extract carotenoids and lipids from Heterochlorella luteoviridis. Bioresour. Technol. 2017, 224, 753-757. [CrossRef]

32. Del Hierro, J.N.; Herrera, T.; García-Risco, M.R.; Fornari, T.; Reglero, G.; Martin, D. Ultrasound-assisted extraction and bioaccessibility of saponins from edible seeds: Quinoa, lentil, fenugreek, soybean and lupin. Food Res. Int. 2018, 109, 440-447. [CrossRef]

33. Kobus, Z. Dry matter extraction from valerian roots (Valeriana officinalis L.) with the help of pulsed acoustic field. Int. Agrophys. 2008, 22, 133-137.

34. Pan, Z.; Qu, W.; Ma, H.; Atungulu, G.G.; McHugh, T.H. Continuous and pulsed ultrasound-assisted extractions of antioxidants from pomegranate peel. Ultrason. Sonochem. 2012, 19, 365-372. [CrossRef]

35. Patience, N.A.; Schieppati, D.; Boffito, D.C. Continuous and pulsed ultrasound pectin extraction from navel orange peels. Ultrason. Sonochem. 2021, 73, 105480. [CrossRef]

36. Christou, A.; Stavrou, I.J.; Kapnissi-Christodoulou, C.P. Continuous and pulsed ultrasound-assisted extraction of carob's antioxidants: Processing parameters optimization and identification of polyphenolic composition. Ultrason. Sonochem. 2021, 76 105630. [CrossRef]

37. Medina-Torres, N.; Ayora-Talavera, T.; Espinosa-Andrews, H.; Sánchez-Contreras, A.; Pacheco, N. Ultrasound assisted extraction for the recovery of phenolic compounds from vegetable sources. Agronomy 2017, 7, 47. [CrossRef]

38. Singleton, V.L.; Orthofer, R.; Lamuela-Raventós, R.M. Analysis of total phenols and other oxidation substrates and antioxidants by means of folin-ciocalteu reagent. Methods Enzymol. 1999, 299, 152-178.

39. Szymanowska, U.; Baraniak, B.; Bogucka-Kocka, A. Antioxidant, Anti-Inflam-matory, and Postulated Cytotoxic Activity of Phenolic and Anthocyanin-Rich Fractions from Polana Raspberry (Rubus idaeus L.) Fruit and Juice-In Vitro Study. Molecules 2018, 23, 1812. [CrossRef]

40. Zhang, Z.; Chang, Q.; Zhu, M.; Huang, Y.; Ho, W.K.K.; Chen, Z.Y. Characterization of antioxidants present in hawthorn fruits. J. Nutr. Biochem. 2001, 12, 144-152. [CrossRef]

41. Liu, J.L.; Yuan, J.F.; Zhang, Z.Q. Microwave-assisted extraction optimised with response surface methodology and antioxidant activity of polyphenols from hawthorn (Crataegus pinnatifida Bge.) fruit. J. Food Sci. Technol. 2010, 11, 2400-2406. [CrossRef]

42. Abbaspour-Gilandeh, Y.; Kaveh, M.; Fatemi, H.; Aziz, M. Combined Hot Air, Microwave, and Infrared Drying of Hawthorn Fruit: Effects of Ultrasonic Pretreatment on Drying Time, Energy, Qualitative, and Bioactive Compounds' Properties. Foods 2021, 10, 1006. [CrossRef]

43. Ebrahimzadeh, M.A.; Bahramian, F. Antioxidant Activity of Craaegus pentaegyna Subsp. elburensis Fruits Extracts Used in Traditional Medicine in Iran. Pak. J. Biol. Sci. 2009, 12, 413-419. [CrossRef] [PubMed]

44. Tadic, V.; Dobric, S.; Markovic, G.; Dorevic, S.; Arsic, I.; Menkovic, N.; Stevic, T. Anti-inflammatory, gastroprotective, free-radicalscavenging, and antimicrobial activities of hawthorn berries ethanol extract. J. Agric. Food Chem. 2008, 56, 7700-7709. [CrossRef] [PubMed]

45. Li, M.; Chen, X.; Deng, J.; Ouyang, D.; Wang, D.; Liang, Y.; Chen, Y.; Sun, Y. Effect of thermal processing on free and bound phenolic compounds and antioxidant activities of hawthorn. Food Chem. 2020, 332, 127429. [CrossRef] [PubMed]

46. Froehlicher, T.; Hennebelle, T.; Martin-Nizard, F.; Cleenewerck, P.; Hilbert, J.; Trotin, F.; Grec, S. Phenolic profiles and antioxidative effects of hawthorn cell suspensions, fresh fruits, and medicinal dried parts. Food Chem. 2009, 115, 897-903. [CrossRef]

47. Maran, J.P.; Priya, B. Ultrasound-assisted extraction of polysaccharide from Nephelium lappaceum L. fruit peel. Int. J. Biol. Macromol. 2014, 70, 530-536. [CrossRef]

48. Kumar, K.; Srivastav, S.; Sharanagat, V.S. Ultrasound assisted extraction (UAE) of bioactive compounds from fruit and vegetable processing by-products: A review. Ultrason. Sonochem. 2021, 70, 105325. [CrossRef]

49. Dezhkunov, N.V.; Francescutto, A.; Ciuti, P.; Sturman, F. Temperature Dependence of Cavitation Activity at Different Ultrasound Intensities. In XVI Session of the Russian Acoustical Society; Andreyev Acoustics Institute: Moscow, Russia, 2005. 
50. Contamine, R.F.; Wilhelm, A.M.; Berlan, J.; Delmas, H. Power measurement in sonochemistry. Ultrason. Sonochem. $1995,2,43-47$. [CrossRef]

51. González-Centeno, M.R.; Knoerzer, K.; Sabarez, H.; Simal, S.; Rosselló, C.; Femenia, A. Effect of acoustic frequency and power density on the aqueous ultrasonic-assisted extraction of grape pomace (Vitis vinifera L.)-A response surface approach. Ultrason. Sonochem. 2014, 21, 2176-2184. [CrossRef]

52. Al-Dhabi, N.A.; Ponmurugan, K.; Jeganathan, P.M. Development and validation ofultrasound-assisted solid-liquid extraction of phenolic compounds from waste spent coffee grounds. Ultrason. Sonochem. 2017, 34, 206-213. [CrossRef]

53. Raza, A.; Li, F.; Xu, X.; Tang, J. Optimization of ultrasonic-assisted extraction of antioxidant polysaccharides from the stem of Trapa quadrispinosa using response surface methodology. Int. J. Biol. Macromol. 2017, 94, 335-344. [CrossRef]

54. Wang, W.J.; Ma, X.B.; Xu, Y.T.; Cao, Y.Q.; Jiang, Z.M.; Ding, T.; Liu, D.H. Ultrasound-assisted heating extraction of pectin from grapefruit peel: Optimization and comparison with the conventional method. Food Chem. 2015, 178, 106-114. [CrossRef] [PubMed]

55. Minjares-Fuentes, R.; Femenia, A.; Garau, M.C.; Meza-Velázquez, J.A.; Simal, S.; Rosselló, C. Ultrasound-assisted extraction of pectins from grape pomace using citric acid: A response surface methodology approach. Carbohydr. Polym. 2014, 106, 179-189. [CrossRef] [PubMed]

56. Rodrigues, S.; Fernandes, F.A.N.; de Brito, E.S.; Sousa, A.D.; Narain, N. Ultrasound extraction of phenolics and anthocyanins from jabuticaba peel. Ind. Crop. Prod. 2015, 69, 400-407. [CrossRef]

57. Hosseini, S.S.; Khodaiyan, F.; Kazemi, M.; Najari, Z. Optimization and characterization of pectin extracted from sour orange peel by ultrasound assisted method. Int. J. Biol. Macromol. 2019, 125, 621-629. [CrossRef] [PubMed]

58. Rodrigues, S.; Pinto, G.A.; Fernandes, F.A. Optimization of ultrasound extraction of phenolic compounds from coconut (Cocos nucifera) shell powder by response surface methodology. Ultrason. Sonochem. 2008, 15, 95-100. [CrossRef]

59. Kobus, Z.; Wilczyński, K.; Nadulski, R.; Rydzak, L.; Guz, T. Effect of Solvent Polarity on the Efficiency of Ultrasound-assisted Extraction of Polyphenols From Apple Pomace. In Proceedings of the IX International Scientific Symposium Farm Machinery and Processes Management in Sustainable Agriculture, Lublin, Poland, 20-22 November 2017.

60. Kobus, Z.; Kusinska, E. Influence of physical properties of liquid on acoustic power of ultrasonic processor. TEKA Kom. Mot. Energ. Roln. 2008, 8, 71-78. 